\title{
The Economics of Enforcement: The Case of OSHA.
}

\author{
Michael L. Marlow
}

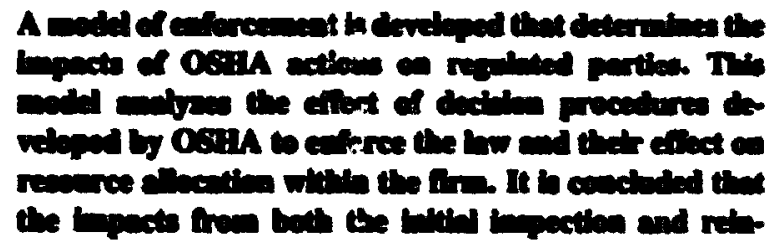

\section{INTRODUCTION}

The Oocupational Safety and Health (OSH) Act of 1970 provides for safe:y regulation of 5 million workplaces. This law is one of the many new types of regulation introduced in the 1970 s to regulate the economy on a nationwide basis. A major problem that hinders policy makers is the effective enforcement of such regulation. Enforcement of the act is the responsibility of the Oxc:pational Safety a-d Health Administration (OSHA).

Previous research has concluded that OSHA has not exerted a significant impact on regulated firms. Chelius (1974) and Smith (1975) find that OSHA has not exerted a significant impact on injury rates, and Chelius concludes that even though injury rates decreased after the OSH Act, these decreases are not related to OSHA but rather to drops in business activity and young worker employment. Gleason and Barnum (1975) find that the costs imposed on firms for noncompliance are trivial in omparison with the opportunity costs of investme is unrelated to the correction of violations. Viscusi (1979) concludes that OSHA has failed to exert a significant impact on the actual or planned safety investments of firms.

This paper examines the powers of OSHA by developing a model of enforcement that details the impact OSHA can exert on firms and yields insights into this agency's historical progress toward legislated goals. It differs from previous studies in the following ways. First, this paper examines the effoctiveness of

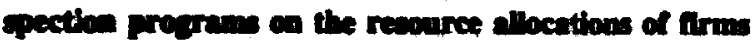

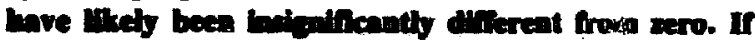
OSHA is to berene the enocetion of hiviry control

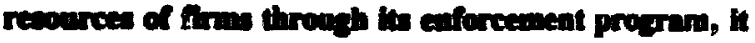

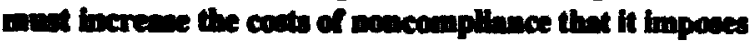
on firme.
\end{abstract}

initial and reinspection programs whereas in the study oy Gleason and Barnum (1975), for example, only initial inspections are considered. Second, this model confines violations to those that are penalized, not total violations. When a firm expects with great certainty to be found in violation but not penalized, it has less incentive to consider correction. Third, this paper does not consider the impact of OSHA on injury rates. To the extent that injuries are the result of both "unsafe" job habits and engirecring controis, OSHA"s impact on injuries will likely be insignificant from zero since it does not control the job habits of workers.' Fourth, this paper analyzes enforcement on the state and national level. One of the characteristic problems with previous research is that analysis of enforcement parameters based on aggregate data does not provide information on how close thesc values are to the parameter values derived on a state basis. This paper offers insights into the issue of whether previous research provides both reliable and general results.

Since the present study most closely resembles the study by Viscusi (1979), a separate and detailed discussion of the important differences between these two is presented here. One difference is that Viscusi assumes workers desire constant work place quality, generating the resuit that workers cannot increase their real wages by increasing their personal level of control effort. On the contrary, we argue that if OSHA exerts a significant effect on firms, it causes workers to become more safety-conscious since em-

\footnotetext{
1 See U.S. Department of Commerce (1977). Only recintly, and very rarely, have the courts held firms liable for unsafe acts by employees. See, for example, Brennan v. OSHRC and Conrad Precision Industries (2 OSHC 1137).
} 
ployers would attach relatively higher premiums to personal safety control. In addition, if OSHA were able to increase information on risk to workers, OSHA would have the power to increase both the market wages and the costs of firms. The opposite conclusion is found by Viscusi: as OSHA increases the control efforts of firms, workers decrease their level of personal control. This conclusion leads Viscusi to the following policy consideration: there is a danger that stringent enforcement may increase work hazards because of decreases in the personal control efforts of workers. This paper's conclusion is quite different: if OSHA is to increase injury control, it must increase its level of enforcement.

The other major difference between this paper and Viscusi concerns the testing of the enforcement mode? Viscusi examines the impact of certain (SSHA peniliy and inspection variables on investment in contr.: equipment by firms and worker injury rates. No significant relationship is found between these variables after it is recognized that OSHA's historical use of enfercement sanctions have caused trivial costs to lirms. This paper recognizes that previous studies have found irivial costs to firms and addresses the following questions. How may OSHA affect the compliance of regulated parties? Has OSHA affected certain segments of the nation." To what level must sanctions be raised to affect compliance agnificantly"?

\section{ENFORCEMENT MODEL}

Effective enforcement of t ules relies on both information gathering and penalizing activities. Information gathering is the acquisition of information on the compliance decisions of firms. Searches may take many forms: inspection, monitoring activity, and complaint information from outside parties. The principal means by which OSHA gathers information on compliance activity is through work place inspections. During fiscal 1977 OSHA conducted 196,078 inspections. ${ }^{2}$ Penalties for detected siolations ars usually of two types: nonserious an, 1 serious. Eact. nonserious violation, with a civil penalty of up to Sl.060. has a direct relationship to icb safety and health but probably would not wause death or serious injury. ${ }^{3} \mathrm{~A}$ serious violation sarries a signilicant probability that death or serious physical harm could result and assumes the employer knew, or should have known of, the violation ${ }^{*}$

\footnotetext{
3 See Office of Management Data and Statistical Analysis (1977).

3 OSH Act (1970), Soc. 17 (b)

- OSH Act (1970), Sec. 17 (b)
}

Together the information gathering and penalizing powers of agencies lead to potential costs to violators. Both activities are needed to generate an expected loss for a firm out of compliance with various rules. For example, if a regulated firm expects with great certainty to be found in violation but not penalized for a violation, it will have less incentive to correct the violation. When applied in combination, the inspection and penalizing activities determine whether it "pays" for lirms to comply with rules.

A description of the cost finction for the firm in sume state of noncompliance is

$C_{i}=C\left(\alpha, \gamma_{i}, \dot{\lambda}_{i}, \pi, \rho_{i}\right)$

where

$$
\begin{aligned}
& C_{1}=\begin{array}{l}
\text { expected cost in dollars for violation of } \\
\text { rule } i, \text { for } i=1,2, \cdots, \eta
\end{array} \\
& i=\quad \begin{array}{l}
\text { probability that OSHA acquired informa- } \\
\text { lion on compliance for all } \eta \text { rules }
\end{array} \\
& i_{i}=\quad \begin{array}{l}
\text { penalty in dollars for violation of rule } i \text {, for } \\
i=1,2, \cdots, \eta
\end{array} \\
& i_{i}=\quad \begin{array}{l}
\text { percentage of inspections that penalize vio- } \\
\text { lations of rule } i, \text { for } i=1,2, \cdots, \eta
\end{array} \\
& \Pi=\quad \begin{array}{l}
\text { percentage of inspections that penalize vio- } \\
\text { lacions of at least one rule }
\end{array} \\
& i_{i}=\quad \begin{array}{l}
\text { cost in dollars associated with continued } \\
\text { violations of rule } i \text {, apart from penalties. for } \\
i=1,2, \cdots, \eta
\end{array}
\end{aligned}
$$

The first four arguments are called policy parameters because they represent values determined by OSHA, which applies its discretionary enforcement power to influence the expected cests of noncompliance for parties with individual rules through applications of these policy parameters. The remaining arguments are salled cost parameters because they $m$ easure all other costs not directly related to enforcement.

All four types of policy parameters exert positive effects on the expected costs of noncompliance for the firm. Parameter $\alpha$ reflects the frequency aspect of inspections; the more inspections corrducted, the more firms may expect to be found in violatio:. Parameters $\lambda_{i}$ measure one aspect of the intensity character stic in inspections; the greater the value of all $\lambda_{i}$, the greater the potential cost from violation of rule $i$. Parameter $\pi$ represents the rate of penalizing all viclations of rules by OSHA during inspections. Both frequency and intensity characteristics are allowed for. The remaining types of policy parameters are the 
potential penalties firms face for specific violations of rule $i$ observed during inspections. Values of $i_{i}$ represent the intensity characteristics of penalizing activity, while frequency aspects are displayed in $\lambda_{i}$.

Cost parameters $\rho_{i}$ represent all other costs that may be incurred by a firm subject to inspection. While these parameters may represent many different types of costs, we confine our discussion to the impa:t of inspection on workers' wages. While workers are considered safety-conscious, they do not possess perfect information on the various risk characteristics associated with alternative emplcyments, and market wages do not reflect perfect compensation for occupational risk. OSHA may increase information on risk to workers through its identification of noncomplying firms, which would increase market wages and the costs of the firm as well. But the degree of identification depends on the characteristics of the rule set that OSHA enforces on firms. There is evidence that OSHA's enforcement program is not aimed at disseminating information on previously unperceived risks to workers and that consequently it has not heen successful at increasing worker's compensation for previously uncompensated risk. ${ }^{5}$ Owing to the probable trivial impact on market wages exerted by OSHA, the effect of all $\rho_{i}$ on the costs of noncompliance is assumed to be positive and constant.

The loss function for the regulated firm is defined as $^{\mathrm{o}}$

$$
E(L)=\sum_{i=1}^{n} x_{i i} \lambda_{i} \Pi
$$

where $i=1,2, \cdots, \eta$ denotes the complete set of rules This function utilizes all the policy parameters in equation (1) in determine the relevant characteristics of the incentive structure facing firms for compliance with rules. This loss function has several interesting properties regarding the effectiveness of enforcement activity on the compliance decisions of firms. First, not only the absulute level of penalty imposition defines the expected costs of violations; the irequency and intensity characteristics together determine the value of the loss potential. Second, lirms must be cited and penalized for violations to affect the costs of their noncompliance. For example, if OSHA observed, but not penalized, violations of rule $i$, it would have a trivial impact on the preregulatory costs of firms for not adopting rule $i$.

\footnotetext{
${ }^{3}$ See Bolle (1977) and Comell and Weingast : 1976)

- A similar function is developed in Gleason and Bamum ( :975). The function in our study, though, confines violations only to those that have been penalized.
}

The loss function in equation (2) defines the expected loss facing firms in nuncompliance in a time period that had not been previously inspected in a given jurisdiction. It is this cost that firms weigh against the returns from alternative investments. Assume there is an alternative investment the size of the outlay necessary for compliance with OSHA rules in a given period. If the return on this alternative investment is greater than $E(L)$ in the same period, the firm does not invest in corrective activity. But if $E(L)$ is greater than the alternative return, the firm does invest in corrective activity. If a firm is inspected in the policy period, the penalties $\gamma_{i}$ are the expected costs of noncompliance with each penalized violation.

\section{THE ENFORCEMENT PROGRAMS OF OSHA}

\section{The Initial Inspection Program}

The value of $E(L)$ is estimated in the following manner. ${ }^{7}$ Fiscal 1977 is the policy period within which estimates are made. The probability of initial inspection $\alpha$ is estimated by dividing the number of initial inspections by the number of regulated firms. Initial inspections are inspections in the policy period that are not follow-ups of previous inspections in the same policy period. Violations are of two types: serious and nonserious. The percentage of detected violations that are serious and fined is the proxy for $\lambda_{1}$, the percentage of penalized violations that are serious. $A$ similar estimate is made for penalized nonserious violations $\lambda_{2}$. The sum of $\lambda_{1}$ and $\lambda_{2}$ is unity. Average penalties for serious and nonserious violations $\lambda_{1}$ and $\lambda_{2}$ are estimated by dividing total penalties by the number of violations with penalties. The percentage of initial inspections that penalize violations $\Pi$ is estimated by the percentage of all inspections that penalize violations.

Ideally $\mathrm{tl}$ a expected loss in cquation (2) would be estimated on an industry basis since enforcement levels can be expected to be related to risk levels. Unfortunately such data are not available; rather, such estimates are made on both the state and national levels. Table 1 displays both high and low values for each paiameter on the state level and the stundard deviation for each parameter. The mean shown is the national mean. From Tcheh ycheff's inequality, the probability of drawing a sample observation whose value is more than 3 standard

\footnotetext{
7 All enforcement and compliance data were otkained from the Office of Management Data and Staristical Anslysis !1977). The data on the number of firms were obtained from the Offict of the President (1973).
} 
TABLE 1. Estimates of Enforcement Parameters for Fiscal 1977

\begin{tabular}{lcccc}
\hline & $\begin{array}{c}\text { High } \\
\text { Value }\end{array}$ & $\begin{array}{c}\text { Low } \\
\text { Value }\end{array}$ & $\begin{array}{c}\text { Standard } \\
\text { Deviation }\end{array}$ & Mean \\
\hline Initial inspection $\alpha$ & 0.2629 & 0.0063 & 0.0435 & 0.037 \\
Reinspection $\alpha_{R}$ & 0.7483 & 0.050 & 0.1535 & 0.190 \\
Serious penalty $\gamma_{1}$ & 909.09 & 121.85 & 159.37 & 291.21 \\
Nonserious penalty $\gamma_{2}$ & 198.18 & 11.79 & 30.51 & 65.75 \\
Percent serious $\lambda_{1}$ & 0.86 & 0.01 & 0.2334 & 0.46 \\
Percent nonserious $\lambda_{2}$ & 0.99 & 0.14 & 0.1100 & 0.54 \\
Noncos. Jiance $\Pi$ Expected loss $E(L)$ & 0.92 & 0.15 & 0.2259 & 0.49 \\
Expected ioss $E_{R}(L)$ & 34.70 & 0.50 & 5.44 & 3.90 \\
& 29.84 & 0.76 & 16.14 & 20.06 \\
\hline
\end{tabular}

deviations away from the mean is 0.0027 . In terms of the loss perameters $E(L)$ this corresponds to a limit of $-\$ 12.42$ to $\$ 20.22$. These estimates suggest that the likely eniorcement impact from OSHA on firms is insignificant from zero, so we argue that the national estimates are both reliable and general. This allows us to carry tine rest of the discussion in terms of the national estimatc.

During fiscal 1977 the initial inspection rate was 3.7. estimates applied to approximately 96 percent of all firms. A firm that had not been initially inspected in fiscal 1977 and was in noncompliance could expect a cost of $\$ 3.90$ for noncompliance. This implies that an invesiment in correction yielded a return of $\$ 3.90$ to the firm that had not been initially inspected. In 1974 the National Association of Manufacturers surveyed its members as to the size of the investment necessary to correct all their violations. ${ }^{8}$ Average estimates ranged from $\$ 35,000$ for firms with 100 or fewer employes to over $\$ 4.5$ million for those with more than 5000 employees. With the lower estimate of $\$ 35,000$, a return of $\$ 3.90$ was associated with a return of 0.01 percent on an investment in correction in fiscal 1977. An alternative investment that yield d a return of 7 percent. for example, would have generated $\$ 2.450$ in revenue to the firm. The data in Table 1 indicate that firms in noncompliance and not initidly ins int during fiscal 1977 were likely to have chicsen alternative investments as long as correction irvestments were yielding noncompetitive rates of return.

If a firm was inspected once in any of the policy periods. the penalties would become the expected costs for each violation cited and penalized. By multiplying the average number of violations per initial inspection by the penalty. an estimate of the

\footnotetext{
- See Gicupational Hazards (1974. p. 8).
}

average cost of an initial inspection is made. This cost would have applied to approximately 4 percent of all firms in fiscal 1977. The average number of serious violations with penalties per initial inspection was 0.19 in fiscal 1977; the average number of nonserious violations with penalties per initial inspection was 044 ; the estimate of the average costs of initial inspections was $\$ 103.26$. The imposition of this cost would have been considered trivial by firms in this category faced with the alternative of an investment unrelated to correction. The initial inspection program of OSHA had the likely effect of exertiny an insignificant from zero impact on the resource allocation of firms inspected once during fiscal 1977 since the initial inspection program produced insufficient incentives for increasing firms' control efforts.

\section{The Reinspection Program}

OSHA also enforces the OSH Act through the reinspection of firms previously deternined out of compliance. An estimate is made of $E_{R}(L)$, the expected cost of continued noncompliance for firms not reinspected and not correcting violations detected during initial inspections. This cost is estimated by redefining the policy parameters in equation (2) 10 correspond to OSHA's reinspection program. The subscript $R$ will denote this corresponilence.

The values of ${ }^{\prime} R_{R}, \lambda_{R_{1}}$, and $\Pi_{R}$ remain unchanged fom their initial counterparts in Table 1. Unfortunately, data are unavailable to estimate new values for these parameters in relation to the reinspection program of OSHA. The use of the initial values of the parameters $\gamma_{i}$ and $\lambda_{i}$ probably produces underestimates for the true values of these parameters since it is likely that inspectors would cite and penalize continued violations detected during the reinspections more frequently and severely than those de- 
tected during the initial inspection. The use of $\lambda_{1}$ probably produces an underestimate of $\lambda_{k 1}$ sirce reinspections are to focus on the serious violations of initial inspections. ${ }^{9}$ Consequently. $\lambda_{2}$ is probably an overestimate of $\lambda_{n 2}$. The use of $i_{i}$ probably produces an underestimate of $\gamma_{R i}$ since it is likely that inspectors propose higher penalties for continued violations. The consequence of using $\boldsymbol{n}$ as a proxy of $\Pi_{R}$ is indeterminate since there are no data on the relative differences in compliance rates between the two types of inspections. Still the estimates of $E_{R}(L)$ provide iniormation on the costs of continued violations for firms and indicate whether sufficient incentives exist fo: the correction of violations cited and penaized previously by OSHA in the same policy period. The probability of reinspection $\alpha_{n}$ is estimated by dividing the number of reinspections by the number of initial inspections. The size of the standard deviation of $E_{R}(L)$ allows us to carry out this discussion on the national level.

Table I displays the reinspection policy parameters and the estimates of $E_{R}(L)$. The percentage of initial irspections followed by reinspections in fiscal 1977 was 19, implying that roughly 1 percent of all firms w:re reinspected during this year. ${ }^{10}$ With an estimate of $\$ 35,000$ for the necessary investment in correction, a return of $\$ 20.06$ in fiscal 1977 is associated with a r.:urn of 0.06 percent on an investment in correction. On the other hand, an alternative investment yielding a return of 7 percent $\varepsilon$ serates $\$ 2,450$ i:I revenue to the firm. The data in Table 2 indicate that firms that were initially inspected but not reinspected were likely to have chosen alternative investments since investments in correction yielded noncompetitive rates of retum. The reinspection program had the likely effect of exerting an insignificant from zero impact upon the resource allocations of firms that were initially inspected but not reinspected during this period.

If $a$ firm is reinspected, the penalties $\gamma_{R i}$ become the expected costs for each violation cited and penalized. By multiplying the average number of violations per reinspection by the average penalty, the cost of reinspections is estimated. This cost applies to the 1 percent of all firms that experienced reinspections in each period. Because there are no data on the average number of violations and average penalties per reinspection, the initial inspection estimates of the previous section are used. The average cost of reinspection in fiscal 1977 was $\$ 103.26$, amounting to a return of 0.34 percent on an investment in correction

- See Program and Policy Division ( 1976).

${ }^{10}$ This estimate is derived by multiplying $\alpha$ by $\alpha_{R}$ in this periad. of $\$: 5,000$ and representing a noncompetitive rate of return to the firm. The reinspection program of OSHA exerted an insignificant from zero impact on the resource allocations of firms reinspected once during this period.

\section{A Regrescion Amalysis of Noncompliance}

Regression analysis tests the direction of the relationship between noncompliance and the employment of enforcement parameters by OSHA. An obvious problem is the selection of the appropriate definition of noncompiiance. An extreme definition would be one or more violations of the entire set of standards: noncompliance is a zero-one decision and probably every regulated lirm would be determined in noncompliance. On the other hand, noncompliance can be viewed as a problem of degree, in which degrees of noncompliance are determined by the vigor of the enforcement program and noncompliance is defined by adherence to standards and is also inluenced by discretionary authority. We use $\Pi$ defined above as a measure of noncompliance since it allows OSHA to interpret noncompliance continuously and is expected to exhibit a relationship to its e nployment of enforcement parameters.

The following estimate is outained by ordinary leas -squares using data from the 50 states in fiscal $197 \%$ :

$$
\begin{array}{r}
\Pi=0.107+0.839 \alpha+0.323 \alpha_{R}+0.004 \gamma_{1}+0.002 \gamma_{2} \\
(0.977)(2.20)^{*}(1.62)^{* *}(2.14)^{*} \quad(1.56)^{* *}
\end{array}
$$

(t statistic)

$R^{2}=0.23$

$F(4,47)=3.59 *$

The abbreviations for each of the parameters are defined above and one and two asterisks refer to confintesice levels of 95 and 90 peicent, respectiveiy. Noncompliance II measures the ate of noncompliance tnat is a joint probability (i.e., the probability of being initially in: nected and being penalized, given initial inspection 1. All the enforcement parameters exer: a positive impact on noncompliance, which reinforces the definition of noncompliance as a measure of enforcement vigor. This implies that in jurisdictions where OSHA cites a relatively high percentage of firms for noncompliance, they are more apt to emplcy a relatively high use of economic sanctions, and their employment of enforcement 
parameters is in the proper direction, consistent with the deinition of noncompliance.

\section{CONCLUSION}

The examination of the OSHA enforcement prograrn indicates that OSHA has not beeri stu wessful in achieving its goal of increased work place protection. Impacts from both the initial inspecticin and reinspecion programs on the resource allocations of firms have likely been insignificant from zero. Analysis of the data on the national level leads to reliable and general results with regard to the estimates on the state level. Although the regression analysis indicates that the employment of enforcement parameters is positively related to nuncompliance, the impacts from the initial inspection and reinspection programs are too weak to significantly increase the compliance of firms. If OSHA is to increase the injury control resources of firms above that generated in the private market, it must increase the costs of noncompliance to the poirt of equality with the ra:es of return on alternative investments. As the modei of enforcement indicates, the goal of increased work place protection requires increases in the employment of exforcement parameters.

Our miajor conclusion and that of previous studies is that the enforcement program of OSHA has not produced additional compliance by firms. Weidenbaum and Detina (1978) find that the compliance costs resulting from $\mathrm{OSHA}$ regulation were $\$ 3.2$ bilion in 1976. At first this appears as evidence that OSHA has exerted a significant impaci upon the compliance of firms, but in perspective this compliance cost averages only $\$ 640$ per investment expenditure by each of the approximately 5 million firms under regulation by OSHA. ${ }^{1}$ This expenditure appears very small but may be explained ty considering that lirms invested in occupational injury control long bu:fore the arrival of OSHA. Since potential hazards cost the firm, among many other items, lost production and risk compensation to workers, it is in the nierest of the firm to invest in injury control quipment. Even without OSHA, changes in worker haracteristics, firm output, production methods, and depreciation of existing equipment would generate nestment expenditures by firms. ${ }^{12}$

\footnotetext{
"See Office of the Fresident (1973).

it Supporting evidence of this explanation is that no relationship between OSHA activity and the investment behavior of firms has seen found (Viscusi 1979)
}

Two limitations of this study and their implications for public policy will now be addressed. First, the analysis is limited by the level of the data. If OSHA ittempts to limit their enforcement effort to a small group of firms, it is possibie for this group that OSHA has exerted a significant impact upon injury control decisions. ${ }^{13}$ Such a subset of firms may be selected owing to their relatively high injury rates. Given its limited budget, OSHA may be able to exert a significant impact on these firms by concentrating its enforcement resources on a select group of them. In this case OSHA may be merely acting in a rational manner to make the best use of its limited budget. Second, it is not clear that it is in the interest of society for OSHA to increase significantly the costs of noncompliance that it imposes on firms. At the macroeconomic level such actions may lead to increased product prices and force certain firms out of business. Such price and unemployment increases need be analyzed as costs to society of regulation and be compared with the projected benefits from the government program.

The author would like to tiank Panl B. Downing and the anonymous referees for helpful comments.

\section{REFERENCES}

Bolle, M. J. 1977. Cost-Benefit Studies for OSHA Standards: Use and Misuse, Washington, D.C.: Congressional Research Service.

Bureau of National Affairs. 1975. Occupational Safery and Health Reporter 5(18):44.

Chelius, J. R. Summer-Autumn 1974. The control of industrial accidents: economic theory and empirical analysis, Law and Contemporary Problems 38:730-744.

Chelius. J. R. Summer :979. Eccnomic and demographic aspects of the occupational inquiry problem. Quarterly Review of Economics and Business 19:65-70.

Comell, N., Noll, R., Weingast, B. 1976. Safety regulation, in $\mathrm{H}$. Owen and C. L. Schultzes (eds.). Setting National Priorities: The Coming Dscade. Washington. D.C.: Brookings Institution.

Gleason, D. T., and Bamum J. M. 1975. OSHA sanctions: Implicatiuns for public policy. IRRA 28th Annual Winter Meetings 28:84-92.

Occupational Hazards. Fall 1974. What it's costing industry to comply with OSHA, p. 8.

13 This ap, mach, used by Smith (1975), anaiyzes the Target Industry Program (TIP) of OSHA. No significant impact on injury rates was found. Since analysis of injury rute changes is an indirect test of the eff :xtiveness of enforcement, an examination of noncompliance costs in ?TP would prove useful in future reseanch. 
Office of Managemem Data and Statistical Analysis. 1977. 1-CAR and SPO2 Reports. Occupational Safety and Health Administrotion.

Office of the President. 1973. President's report on occupatioral safery and health, p. 41.

Oi, W. V. March 1975. On evaluating the effectiveness of the OSHA inspection programs. Paper presented at the Department of Lubor Conference on Evaluating OSHA, Annepolis, MD.

Program and Policy Division. April 1976. All About OSHA. Occupational Safery and Health Administration.

Smith, R. S. March 1975. The estimated impact on injuries of OSHA's target industry progran. Paper presented at the Department of Labor Conference on Evaluating OSHA, Annapolis, MD.

U.S. Department of Commence. Jan. 1977. Toward Reg. ulatory Reasonableness.

Viscusi, W. K. Spring 1979. The impact of occupational safety and health regulations. The Bell Journal of Economics 10:117-140.

Weidenbaum, M. L., and DeFina, R. 1978. The Cost of Federal Regulation of Economic Activity, reprint no. 88, Washington, D.C.: American Enterprise Institute.

Accepted 10 April 1981 